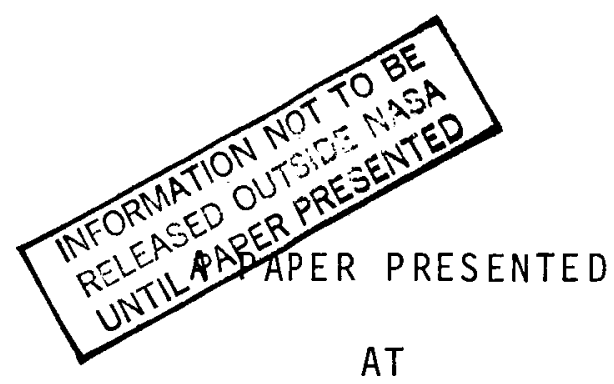

INSTITUTE OF ENVIRONMENTAL SCIENCES

1965 Technical Meeting

and

Equipment Exposition

Apri1 21-23, 1965

prepared by

NUCLEAR AND SCIENTIFIC SERVICES DEPARTMENT RCA SERVICE COMPANY

A DIVISION OF RADIO CORPORATION OF AMERICA Camden, New Jersey
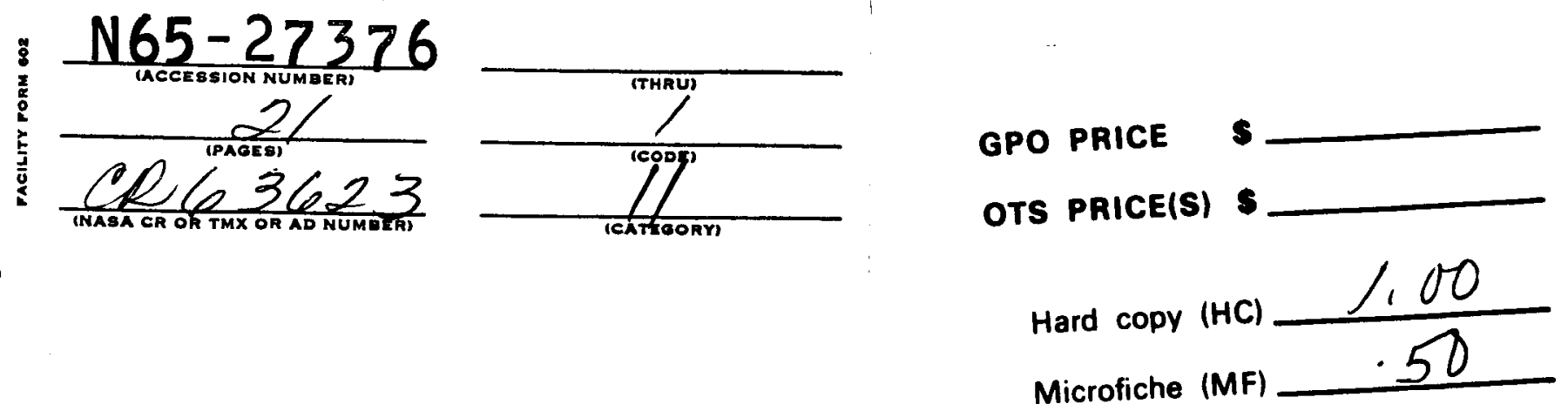

In order to duplicate the temperature of the space sink, which has been estimated to be about $4^{\circ} \mathrm{K}$, the test object is surrounded by a cryogenic wall at liquid helium temperatures. Of course not all tests require that the heat sink be at such a low temperature but there are many that do require these low temperatures. The low pressures of space are attained by a combination of diffusion pumping and cryogenic pumping. The cryogenic walls surrounding the test object are coated with a high absorbtance coating to simulate the radiative heat sink of space. Any molecule leaving an object in space will have a very low probability of ever returning to the object. This property of space is simulated by the ability of the cryogenic walls to pump most molecules that strike it.

A schematic of the vacuum system is shown in figure I. It is basically a triple walled system. The outer chamber is a conventional vacuum vessel and the inner chamber is cooled to liquid nitrogen temperatures and is essentially vacuum tight. The helium panel is inside the inner chamber and is cooled to liquid helium temperatures. Hereafter the helium panel will be referred to as the cryowall. The space inside the inner chamber is pumped by four 35-inch diffusion pumps and the annular space between the outer chamber and the inner chamber is pumped by one 20-inch diffusion fump. A helium refrigerator/11quefier designed and built by Air Products and Chemicals, Inc. as a subcontractor to the RCA Service Company supplies the cold helium to the cryowall. An illustration of the major components of the vacuum facility and refrigerator is show in figure 2. The control console contains the controls and instrumentation necessary for monitoring and operating the vacuum system and helium refrigerator. The motor control 
center contains the circuit breakers for the various electrical components.

There are two of the Iiquefier components shown in figure 2. The box shaped component contains the heat exchangers necessary for precooling the incoming helium to liquid nitrogen temperatures and the cylindrical component contains the expansion engine cylinders and the apparatus necessary to cool the helium to liquid helium temperature. The only major component not shown in figure 2 is the 600 horsepower, non-lubricated helium compressor. A more detailed discussion of each of the components of the vacuum system will be presented next.

\section{DESTGN APPROACH}

\section{A. Vacuum Vessel}

The outer vacuum vessel was designed in accordance with the requirements of Section VIII of the ASME Code for Unfired Pressure Vessels with special attention being paid to the elimination of both real and virtual leaks.

The vacuum vessel is approximately 7.5 feet in diameter and 12 feet long and is fabricated from 30LI stainless steel. All of the parts of the vacuum vessel which are exposed to the vacuum are fabricated from $304 \mathrm{~L}$ stainless steel and the external reinforcing, door hinge, and chamber support columns are fabricated from carbon steel. The requirement for the provision of six model supports, each capable of oarrying load of 4000 pounds in either an upward or dowmard direction, led to a decision to provide a flat bottom plate for the chamber. The flat plate is designed 
to support the four main diffusion pumps and their associated liquid nitrogen traps as well as the vertical load from the model supports. The plate rests on five pipe columns, one at each corner and one in the center, which support the chamber assembly at the second floor control room level and provide sufficient clearance for pump maintenance. A transition section between the plate and the cylindrical botton of the chamber furnishes stiffening for the bottom plate, support for the outer vacuum wall, and contains the model supports and four ducts from the top of the liquid nitrogen traps to the interior of the vacuum chamber.

Since this transition section, or plenum, was designed primarily for structural purposes, it was felt that the joint details and welding techniques which would provide the greatest structural benef1ts might not be compatible with good vacuum welding techntques. In order to insure that any possible leaks in the plenum do not affect the vacuum levels in the chamber, the plenum volume is isolated from the chamber volume and is pumped separately by the mechanical pumping system. The operating pressure in the plenum is on the order of 40 microns. A photograph of the interior of the outer vacuum vessel is shown in figure 3.

\section{B. Inner Chamber Wall}

The inner chamber wall is designed to satisfy two requirements. One function of this wall is to surround the helium cryowall with a surface which is at liquid nitrogen temperature in order to reduce radiant heat transfer to the cryowall, and the other is to provide a means of keeping the gas which evolves from the outer wall from affecting the pressure 
within the ultimate racuum space. The inner chamber itself is a cylinder whth one of the ends removable. The inner chanber is 6.5 feet in diameter and 8.5 feet long. A photograph of the Inner chamber installed in the outer vessel is shown in figure 4. The cylinder and ends are fabricated of single embossed stainless steel sheets which have been electropolished on both sides to reduce the emissivity of the surfaces. In order to insure uniform temperature on the Inner wall while dissipating large heat loads, flow controlling orifices are installed between the liquid nitrogen inlet header and each embossed channel on the Inner wall. A subcooled Ilquid nitrogen system is provided to insure single phase flow of the liquid nitrogen through the embossed channels of the inner wall. The space between the inner and outer walls is pumped by a separate system which maintains a pressure in this annulus which is lower than $1 \times 10^{-6}$ Torr. This guard vacuum eliminates any requirement for baking of the outer chamber.

The vacuum system requires a multiplicity of penetrations in the Inner wall for gaugine, power, control, mechanical motion, viewing, fluid transfer, and model support. This large penetration requirement, together with the requirement for an easily removed door would have made it both difficult and costly to achieve a vacuum-tight assembly of the inner chamber wall.

An engineering decision was therefore made to design an inner wall which would be "diffusion tight" rather than "vacuum tight". By "diffusion tight" it is meant that the seals were designed to offer a low conductance path across the inner chamber wall rather than try to design them to be absolutely vacuum tight. This type desigh would minimize fabrication costs 
without sacrificing performance and would permit frequent handling of the inner wall without worry about damage to vacuum seals.

All penetrations of the inner wall were designed so that the space between mating surfaces was as small as possible and that the conductance path length was as long as possible. For example, electrical penetrations consist of high alunina cermic disks 3.125 inches in diameter and 1.50 inches thick. These disks have holes .004 inches larger in diameter than the wire which goes through them.

The inner wall is supported from the outer wall by means of stainless steel slides on the inner wall resting on rails which are welded to the outer wall. The area of surface contact between the supports is kept to a minimum in order to minimize heat transfer by conduction through the supports. The inlet and outlet liquid nitrogen Iines penetrate the outer vacuum wall through feedthrus located adjacent to the chamber door. The liquid nitrogen transfer lines have bellows expansion joints in the annular space between the inner and outer walls to allow for proper alignment and to reduce thermal stresses In the transfer lines. Connections in the annular space are made with metal gasketed ultra-high vacuum flanges.

Since calculations indicated that large dimensional changes will occur in the inner wall while going from baksout at $480^{\circ} \mathrm{F}$ to operation at $-300^{\circ} \mathrm{F}$ the design provides for pins to locate the door end of the inner wall with respect to the outer wall and to allow the rest of the inner liner to expand on the slide and rail support arrangement. This arrangement reduces thermal stresses in the transfer 1ines. Teflon sliders are inserted between the 
support rails on the outer chamber and the inner wall support slides in order to reduce friction between the ratls and slide.

\section{Pumping System}

The annular volume between the outer and inner chamber walls is pumped by a 20-inch (18,000 liters per second pumping speed) diffusion pump connected to an elbow on the rear head of the chamber. Four 35-inch $(50,000$ liters per second pumping speed) diffusion pumps are supported from the flat bottom plate of the plenum and pump the space inside the inner chamber wall. In order to reduce the forepressure of these main diffusion pumps to as low a value as possible a 10-inch diffusion pump is used as a booster for each of the 35-inch diffusion pumps. The four booster pump forelines and the annulus pump foreline are connected in a common manifold system to a 500 CFM mechanical pump.

Auxiliary valving permits the use of this pump for evacuation of the vacuum jacketed helium transfer lines and of the helium refrigeration system prior to startup.

The annulus diffusion pump and each of the four main diffusion pumps are equipped with a water baffled reservoir type liquid nitrogen trap. Water circulates through the baffles at all times when the pumps are in operation and the trap reservoirs are kept full with an automatic liquid nitrogen level sensing system.

An earlier paragraph described the connection of the main diffusion pumps to the outer vacuum ressel. Since these pumps must evacuate the volume 
inside the inner wall and the inner wall is designed to be removed, a removable transition section is provided from the top of each liquid nitrogen trap to each of four openings in the inner wall. Each section consists of a 35-inch diameter chevron baffle and a 22-gauge stainless steel sleeve. The sleeves are inserted in the space between the liquid nitrogen traps and the openings in the inner chamber wall and the chevron baffles fit across the sleeve openings at the inner chamber wall. Each of the cherron baffles is cooled by conduction from the inner wall. The stainless sleeve also acts as a thermal barrier to reduce heat leak from the ambient temperature top of the liquid nitrogen trap to the liquid nitrogen cooled inner wall.

The controls for the pumping system are interlocked using themocouple gauges as sensing elements. An air operated gate valve will isolate the diffusion pump manifold from the mechanical pump in the event of a rise in diffusion pump manifold pressure above a preset level. A rise in manifold pressure above the desired point will also initiate shutdown and quench of the diffusion pumps.

\section{Cryowall}

In order to provide a low temperature, helium cooled, envelope around the test volume an additional cylinder is installed inside the inner chamber wall. This cylinder, (the cryowall) with one fixed and one end removable, is fabricated of the same embossed material as the liquid nitrogen cooled inner chamber. The cryowall is approximately 7 feet long and 5.5 feet in diameter. In order to provide sufficient molecular conductance from the inside of the cryowall to the diffusion pump ports, the design provides for annular openings at each end of the cylinder. These openings, together with those required for model supports, viewing, gauging and 
introduction of mechanical motion, will allow a test object to "ses" approximately $85 \%$ helium temperature surroundings and $15 \%$ liquid nitrogen temperature surroundings.

In order to reduce heat transfer from the inner chamber wall to the cryowall, the mechanical supports for the cryowall have been fabricated of stainless steel with minimum contact area between the inner chamber wall and the cryowall and the outer surface of the cryowall has been electropolished. Flame sprayed nickel oxide has been used as a coating for the inside of the cryowall in order to provide a surface with high absorbtivity wich will withstand the thermal excursions from the high temperature during bakeout to the low temperature during operation at Iiquid helium temperature.

The inlet and outlet helium transfer lines penetrate the rear head of the outer vacuum wall through specially designed, low heat leak penetrations. Each of the transfer lines incorporates a bellows which permits relative motion between the inner and outer section of the vacuum jacketed transfer Iines.

The inner Iines are extended through the inner chamber wall to the front of the chamber where they connect to the cryowall piping with metal gasketed ultra-high vacuum flanges. Bellows at the point of connection allow for some misalignment and for the large dimensional changes which occur between bakeout and operation at the low temperatures. A radiation baffle which is cooled to Ilquid nitrogen temperature by conduction shields the helium transfer 
line in the annular space between the inner and outer chamber walls.

Two systems are used to monitor temperatures of the cryowall. Helium filled vapor bulhs are located in the transfer lines at the point of connection to the cryowall. Since the vapor pressure of helium changes approximately eighteen pounds per square inch for a change in temperature from $4.2^{\circ} \mathrm{K}$ to $5.2^{\circ} \mathrm{K}$, an accurate measurement of the hellum supply and return temperature in this temperature range is possible. Since the ratio between the warm and cold volumes of the vapor bulb system as well as the charge pressures are known the vapor bulbs are used as gas thermometers with some sacrifice of sensitivity up to about $30^{\circ} \mathrm{K}$.

Carbon resistors are also used to measure the temperature of the cryowall at two points and the temperature of the refrigerant at the inlet and outlet transfer lines. These resistors were prepared for use by alternately heating them to $500^{\circ} \mathrm{F}$ and then cooling them to liquid nitrogen temperatures. Those which survived several cycles of this treatment without change in ambient temperature resistance were then calibrated in nitrogen, hydrogen and helium. In use there is a regulated current of 50 microamperes through the resistor and a potentiometer is used to measure the voltage drop across the resistor. This voltage drop is a measure of the resistance which is in turn a measure of the temperature.

Since there is to some extent thermal isolation of the carbon measuring element from the surface at which the temperature is to be measured, extreme care was necessary to eliminate flow of heat into the resistor from external sources. Ceramic coated \#3LAWG wire was used to connect the resistor to the measuring circuit. This wire was wound around the helium transfer line 
so that adequate heat stationing was provided. The entire assembly was shielded with aluminum foll so that radiant hest from the test losd would not affect the temperature reading.

The cryowall is cooled using liquid or gaseous hellum from a closed-cycle helium refrigerator/1iquefier having a refrigeration capacity of over 1400 watts at Iiquid helium temperature (approximately $5^{\circ} \mathrm{K}$ ). The Ilquefier is capable of furnishing continuously 1820 liters per hour of liquid helium to the cryowall. When operating in the $20^{\circ} \mathrm{K}$ mode, the refrigerator is capable of removing a refrigeration load equivalent to the heat from a 2000 watt load and in the $-300^{\circ} \mathrm{F}$ mode, the heat load may be 5000 watts. All of these temperatures are measured on the exit helium transfer line.

\section{E. Bakeout System}

Radiant heaters are used to bake the inner chamber wall. Of course when the inner chamber wall gets hot the components of the system inside the inner chamber wall get hot also. The heaters are tantalum ribbons supported from the outer chamber wall on ceramic standoff insulators. Two reasons led to this selection of heater element. Sufficient data was not available to Indicate that nichrome would not evaporate during heating in a vacuum and coat the insulators with chrominum and tantalun has a low resistivity compared to nichrome which permitted long series loops rather than parallel hookups, thus minimizing power feedthrough problems. The heater elements are fed from a $50 \mathrm{~kW}$, three-phase, 220 volt Variac and over-temperature protection is provided by a cycling type thermocouple-actuated switch which removes power from the heaters when a preset temperature is reached. 
Strip heaters are welded to the exterior of each diffusion pump trap with insulation applied outside of the beaters. Manually operated circuit breakers permit any combination of the traps to be baked simultaneously. Over-temperature protection is also provided for the trap bakeout system.

A third set of hesters consisting of tantalum ribbon wound on ceramic insulated stainless steel frames is installed above each trap. This heater system is used to warm the traps in the event that a rapid return to ambient conditions is required.

\section{F. Feed-Throughs}

In order to provide maximum usefulness for the system a large number of feed-throughs are provided. With the exception of two nitrogen, two helium, and two gauge penetrations, all penetration flanges on the outer vacuum chamber are identical. Crushed aluminum wire is used as the sealing element. Five 5" diameter sight ports have been provided in the outer vacuum chamber with matching, conduction cooled, pyrex windows in the inner wall. Thermocouple feed-throughs of copper/constantan, chromel/alumel and platinum/platinumrhodium are provided for measuring temperatures from $-350^{\circ} \mathrm{F}$ to $1.000^{\circ} \mathrm{F}$. Electrical power feed-throughs with ratinfs from 5 amperes to 1000 amperes are also available. A bellows sealed push-pull mechanism which has a linear displacement range of three inches and is capable of transmitting a force of 10,000 pounds is arranged to penetrate the inner chamber wall into the space inside the cryowall so that the force may be applied to test specimens inside the cryowall. 


\section{G. Thermal Array}

A thermal radiation array is arranged to f1t inside the cryowall. The thermal array consists of 96 lodine cycle quartz lamps arranged in twelve rows of eight lamps, each with its own reflector assembly. A photograph of the thermal array in place inside the helium cryowall is shown in figure 5. The lamp assemblies are water cooled by conduction through heavy copper bars to water cooling coils in the lamp support structure. The support structure is insulated from the remainder of the chamber and current passed through the structure prevents freezing of the cooling water during periods when the lamps are not in operation and the cryowall is cold.

The lamps are divided into six circuits, each having sixteen 500 watt lamp assemblies. Power to each circuit is controlled by a thyraton regulator which has either a mamual control or may be programmed by a "Precorder" controller.

The thermal array will irradiate a three-foot diameter test specimen six feet long with a heat flux of up to 1000 BTU per square foot per hour.

\section{H. Special Features}

The system is arranged so that it may be returned to atmospheric pressure with dry nitrogen gas. The valves used to admit this gas are interlocked with the roughing pump so that operator error cannot inadvertantly vent the chamber during a test.

The dry nitrogen system is also used for pressure control. A motor driven vacuum leak valve, controlled by an adjustable meter relay with 
High-Iow contacts determines the amount of gas leaked into the chamber. The meter relay is fed from the recorder output of the chamber ionization gauge controller. The leak is controlled manually until the desired pressure decade is reached and the automatic control takes over.

\section{Awxiliary Equipment}

Iiquid nitrogen is circulated through the inner chamber wall with a centrifugal pump. The liquid is stored at approximately $10 \mathrm{psig}$ and the pump increases the pressure to 40 psig. An automatic pressure control valve in the return line keeps the nitrogen in the inner chamber wall under pressure and insures single phase flow in the inner chamber wall.

The pressure at the mechanical pump inlet and at the foreline manifold is indicated by means of thermocouple gauges. Ionization gauges are used to indicate the pressure in the annulus space between the inner and outer chamber wall, in the foreline of the main diffusion pumps, and in the vacuum jacket space of the helium refrigerator dewar.

An ionization gauge is mounted in the test volume inside the cryowall and a cold cathode gauge is mounted on the outside of the rear of the chamber. There is bakable tubulation from the cold cathode gauge to the test volume inside the cryowall.

\section{SYSTEM CAPABILITIES}

The vacuum system is designed so that it can be operated with the 
cryowall removed or with both the cryowall and inner chamber wall removed. The flexibility allows for increased teat volume but with, of course, increased pressure levels. With both the cryowall and inner chamber wall removed the system is just a large vacuum system capable to pressures of about $2 \times 10^{-8}$ Torr. The dimensions of the test volume in this configuration is about 7.5 feet in dianeter and 12 feet in length.

With the inner chamber wall in place but with the cryowall removed the dimensions of the test volume are approximately 6.5 feet in diameter and 8.5 feet in length. The inner chamber wall can dissipate a $10 \mathrm{KW}$ heat load at temperatures less than $-300^{\circ} \mathrm{F}$. The pressure in the test volume in this configuration is about $5 \times 10^{-10}$ Torr.

With the cryowall in place the dimensions of the test volume are 5.5 feet in diameter and 7 feet in length. The cryowall can dissipate a $5 \mathrm{~kW}$ heat load at less than $-300^{\circ} \mathrm{F}$, a $2 \mathrm{KW}$ heat load at less than $20^{\circ} \mathrm{K}$, or a 1.4 KW test load a liquid helium temperatures. The pressure in the test volume in this configuration with the cryowall at $5^{\circ} \mathrm{K}$ is approximately $5 \times 10^{-11}$ Torr. It should be noted that all of the pressures mentioned above are for situations in which there is no test object in the test rolume. 


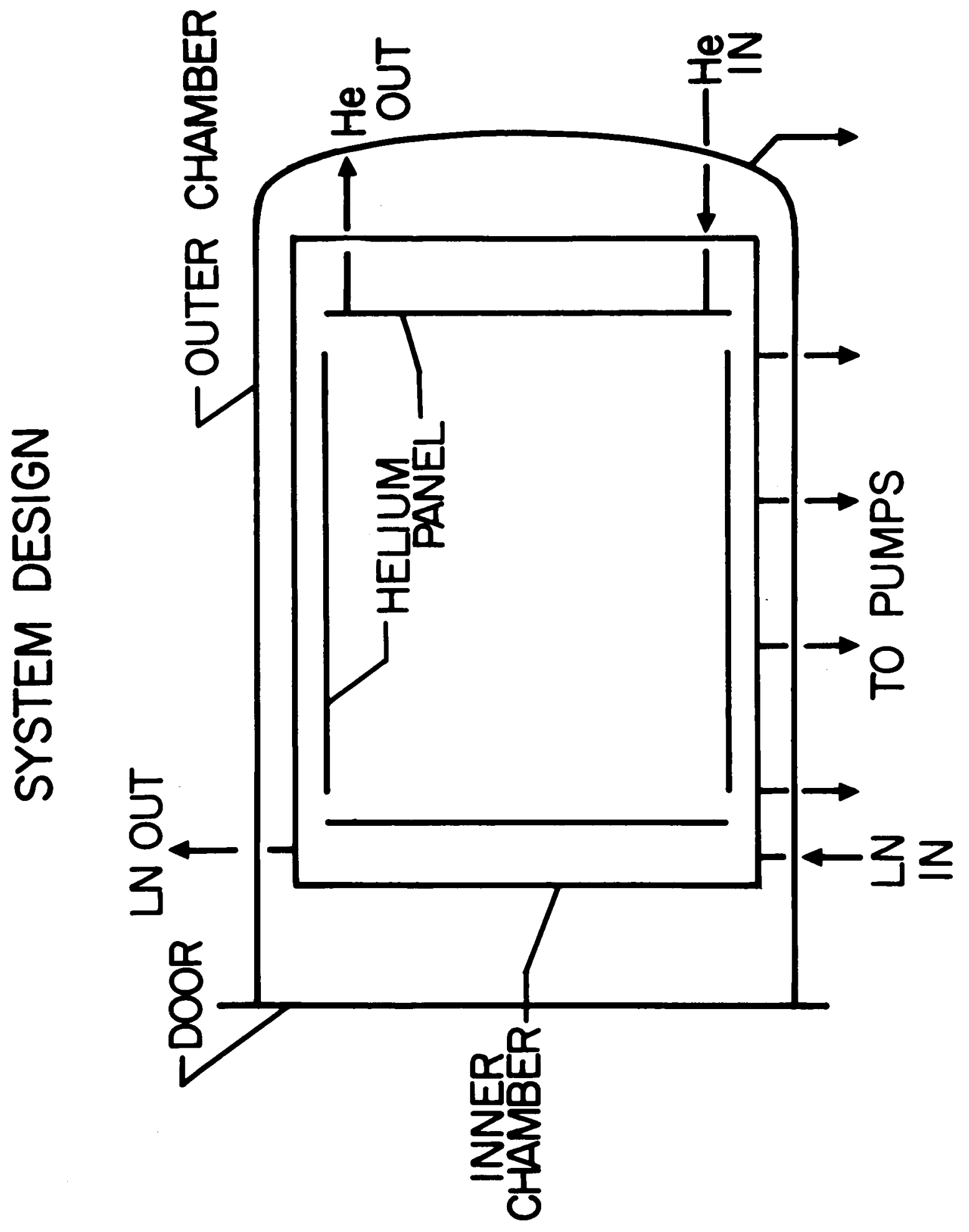

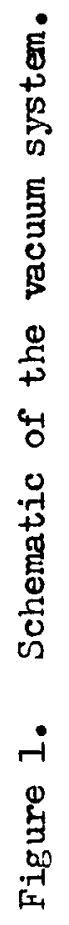




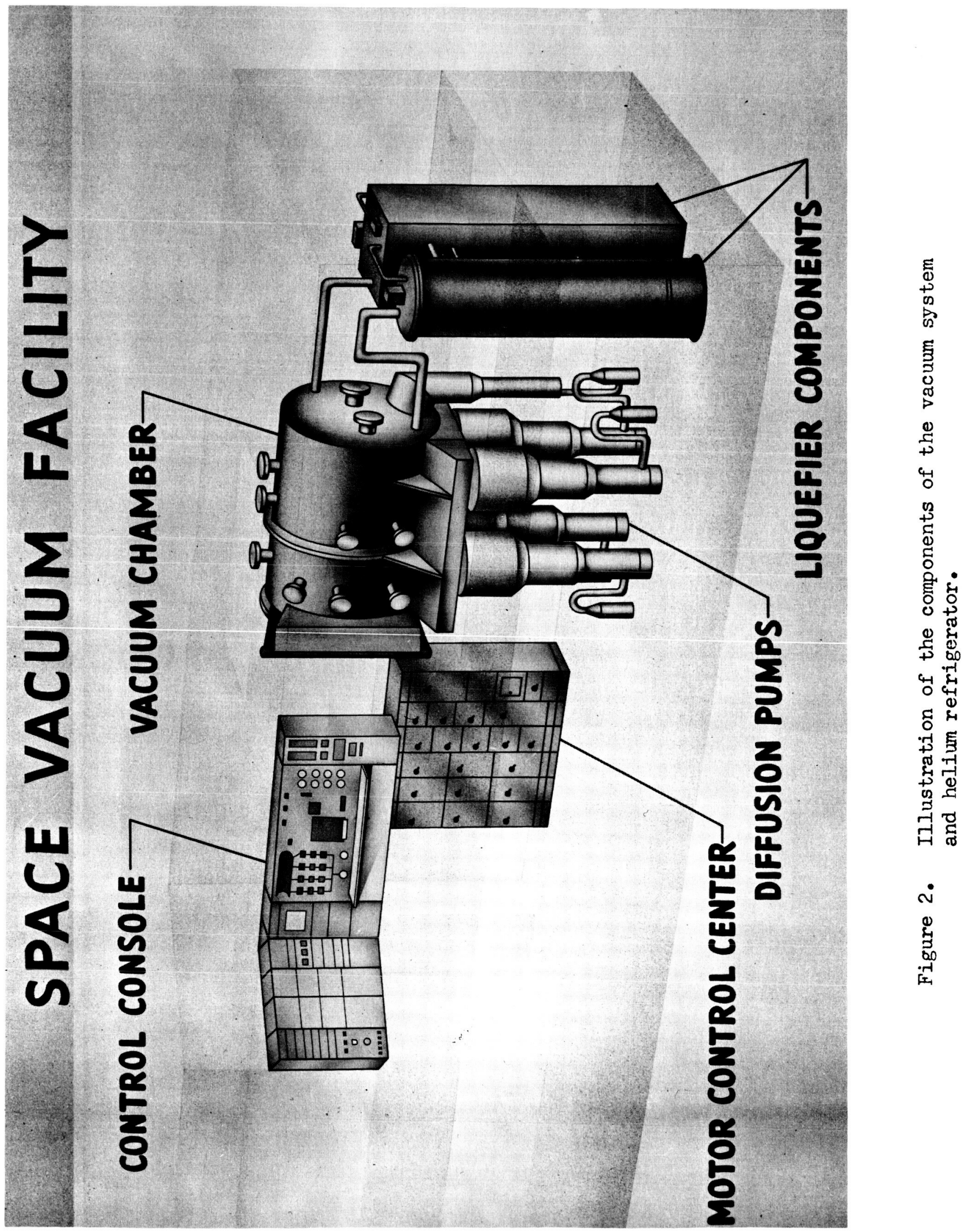




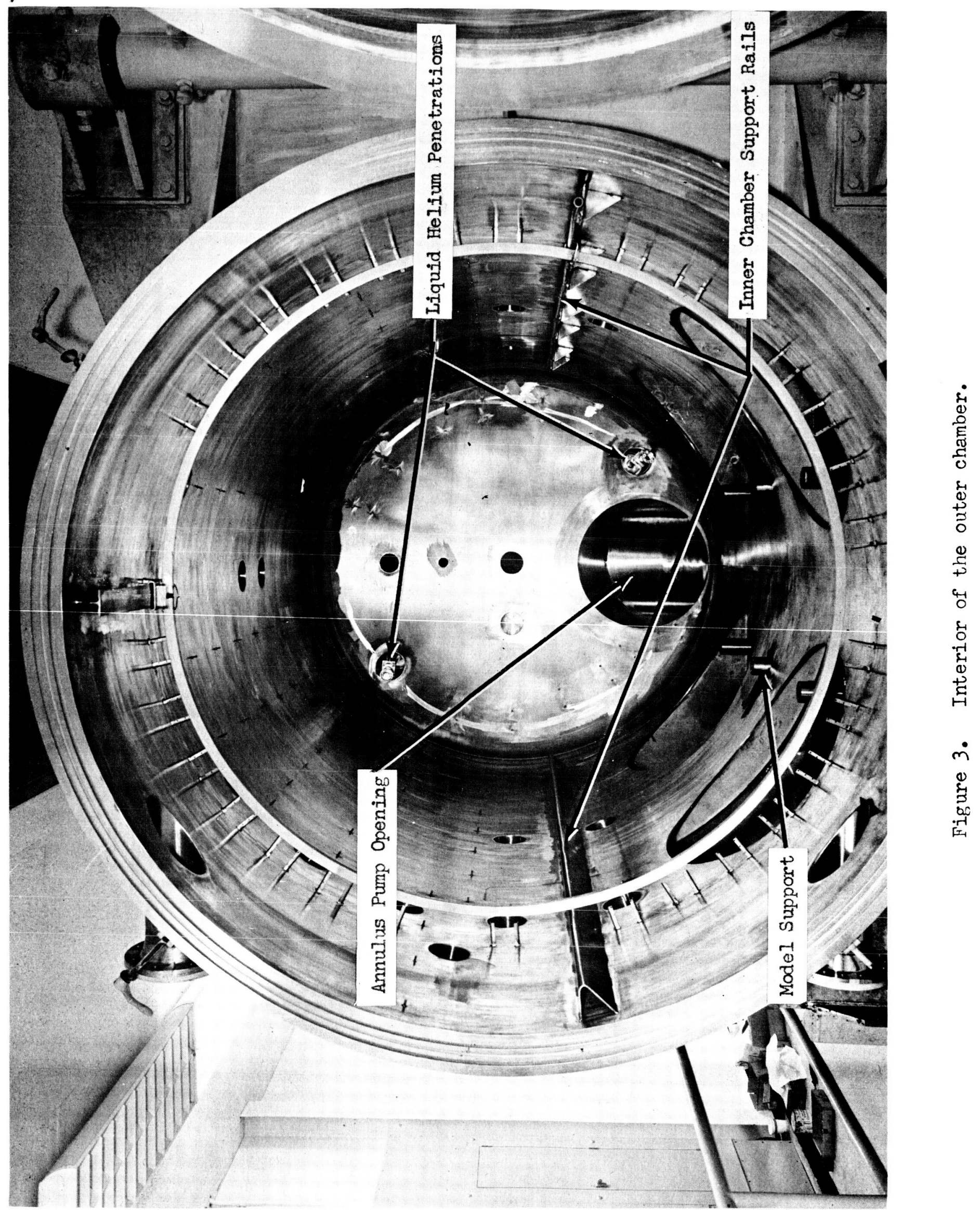




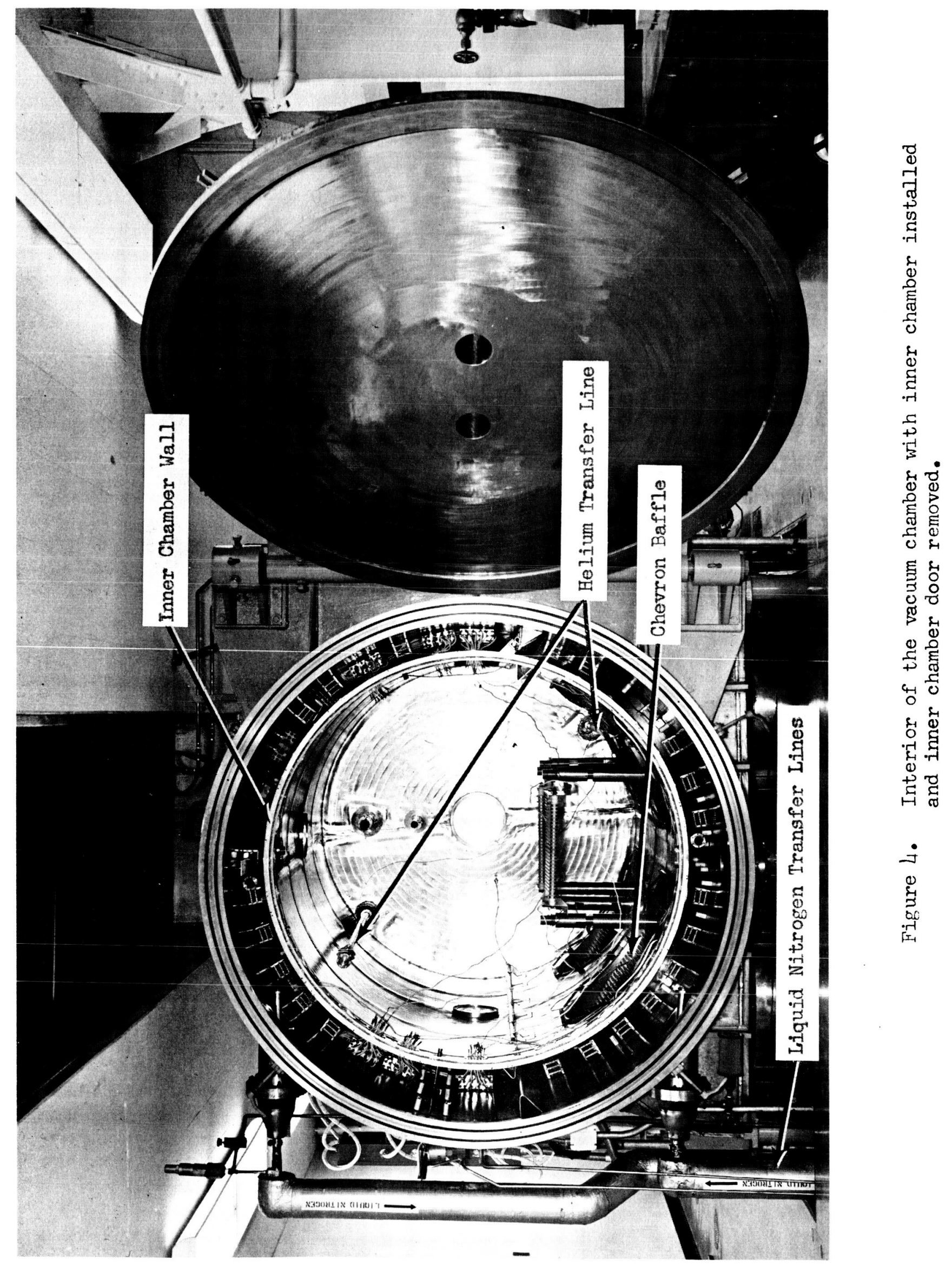




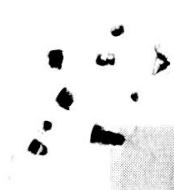

